\title{
How does the Human Resource Department's Client RELATIONSHIP MANAGEMENT IMPACT ON ORGANIZATIONAL Performance in China? Mediate EfFect of Human Capital
}

\author{
Xiaoling Wang \\ Department of Human Resource Management, Shanghai Normal University, Shanghai \\ Yunzhang Hou \\ School of Management, Fudan University, Shanghai \\ Niall Cullinane \\ School of Management, Queen's University of Belfast, Belfast \\ Accepted: February 2015
}

\begin{abstract}
The human resource (HR) department's client relationship management (HRDCRM) is an area of growing research interest in the field of strategic human resource management practices. By introducing human capital as a mediating variable, with one questionnaire sent per enterprise to chief executive officers (CEOs), middle and line managers, and line staff in 260 Chinese enterprises, empirical research on the effects of HRDCRM on organisational performance was conducted. Empirical results indicate that controlling by enterprise ownership and life cycle stage, human capital either completely or partially mediates the effects of HRDCRM's factors on the two parts of organisational performance (new-product performance and business financial performance). The findings show that the combination of HRDCRM as optimal HR management practices and human capital as organisational strategic assets will further improve organisational performance.
\end{abstract}

Key words: China, HR department's client relationship management (HRDCRM), human capital, mediate effect, organisational performance

JEL: M54

\section{$1 \quad$ Introduction}

Fulfilment of the human resource (HR) department's functions plays a very important role in improving organisational performance (Akhtar, Ding \& Ge, 2008). Outside of conventional administration, HR departments are expected to develop multiple roles such as "strategic partner", "change agent", "employees champion", and the like (Gurbuz \& Mert, 2011; Lengnick-Hall, Lengnick-Hall, Andrade \& Drake, 2009; Ulrich, Younger \& Brockbank, 2008). By implication, this requires HR to broaden its services and render its services to different clients, including internal employees, potential employees, customers, government and the community (Shen, 2011). As a consequence of these expected new roles, the activity of HR departments has been reconceptualised under the rubric of "client relationship management". The HR department's client relationship management (HRDCRM) is defined as a series of strategic human resource management (SHRM) practices aiming at optimising a number of goals, namely clients' value, clients' loyalty, and satisfaction with the HR department (Wang \& Peng, 2009).

Studies of the relationships between SHRM practices and organisational performance have attracted much attention (Akhtar et al., 2008; Gurbuz \& Mert, 2011; Huselid \& Becker, 2011), and research findings indicate that SHRM practices have significant and positive effects on organisational performance. However, studies on how SHRM practices bring about an increase in organisational performance are scarce. In short, we know very little about the black box between a firm's HR activities and its bottom line (Youndt \& Snell, 2004). This is true for Chinese literature. 
Prior research examined the factors of HRDCRM and their effects on organisational performance in the People's Republic of China (Wang, 2013), and empirical results indicated that some factors of HRDCRM are positively related to organisational performance, that is: the strategic countermeasure ability of an HR department has positive effects on both new-product performance (NPP) and business financial performance (BFP); organisational attractiveness shows a positive relationship to both kinds of organisational performance; the regulatory mechanism of the HR department is positively related to NPP but not BFP; and observing sustainable business philosophy in HR management practices has a positive effect on BFP but no effect on NPP. But we have no idea of how HRDCRM brings about an increase in organisational performance. Human capital (HUC) subsumes various human resource elements, including cumulative tacit knowledge, competencies, experience and skills, leadership, management skills, and the innovativeness and talents of people (Wang, Peng \& Hou, 2010). HUC has positive effects on organisational performance (Augusto, Couto \& Caiado, 2014), and it is also related to SHRM practices (Kong \& Thomson, 2009). Some scholars have attempted to introduce HUC as a mediating construct between SHRM practices and organisational performance in order to study the impact of SHRM on organisational performance (Daud \& Yusoff, 2011; Wright \& McMahan, 2011).

Extant research on the impact of SHRM practices on organisational performance has been conducted principally in the United States (US) and Europe, but research in this regard is lacking in the context of the People's Republic of China. Apart from the advantages that HRDCRM has over the concept of SHRM practices, together with uncertainty regarding the impact of SHRM practices on organisational performance, this paper considers the impact of HRDCRM on organisational performance by introducing HUC as the mediate variable. We will extend the research on the black box between HRDCRM and organisational performance and will also assist organisation managers to find key paths in order to improve organisational performance and optimise the HR department's management practices in Chinese firms.

The present study attempts to extend the above line of research by developing and testing a conceptual model of the mediate role of HUC in the relationship between HRDCRM and organisational performance in China. It contributes to the extant literature in two ways. Firstly, we establish a conceptual model of the effect of the mechanism of HRDCRM on organisational performance by introducing HUC as the mediate variable. Secondly, we investigate whether HUC mediates the effect of factors of HRDCRM on the two parts of organisational performance controlling enterprises' ownership and life cycle stage. The paper is organised as follows: Section 2 reviews the relationship among SHRM practices, HRDCRM, HUC and organisational performance. Section 3 puts forward research hypotheses based on the conceptual model in Section 2. Section 4 explains the research methods used in the study, including data collection and measures. Section 5 presents the research results, and also outlines the main findings of the research. Section 6 discusses the managerial implications of our findings, briefly outlining the limitations of the present study and potential future research directions. Finally, Section 7 concludes the paper with a brief discussion of the main research findings and results.

\section{Literature review}

\subsection{SHRM practices, HUC and organisational performance}

SHRM practices have been a topic of interest among researchers in the world for some time now. SHRM practices imply a concern with the ways in which HRM is critical to organisational effectiveness. Organisational performance comprises the actual output or results of an organisation as measured against its intended outputs (or goals and objectives) (Richard, Devinney, Yip. \& Johnson, 2009). In order to fully reflect organisational performance, both actual output and potential output should be taken into account. New-product performance (NPP) to some extent shows the potential output of a firm, while business financial performance (BFP) largely represents a firm's actual output, such as total turnover and return on total assets. In addition, Jiang and Zhao (2006) have attempted to use NPP and financial performance to measure company 
performance in the context of China, which accords with our research background. Therefore, organisational performance in this paper is composed of two parts, one is NPP, and the other is BFP.

Previous research examined the relationships between SHRM, HUC and organisational performance. For instance, Youndt and Snell (2004) concluded that HUC mediates the effect of HRM practices on organisational performance. By using empirical research, Lopez-Cabrales, Pérez-Luño and Cabrera (2009) concluded that knowledge mediates the effects of HRM practices on organisational innovative performance. With their empirical research, Chen and Huang (2009) proved that knowledge management capacity played a mediating role between SHRM practices and innovation performance in Taiwan. Extant literature (Youndt \& Snell, 2004; Lopez-Cabrales, Pérez-Luño \& Cabrera, 2009; Chen \& Huang, 2009) has supplied some reference for studying the black box between SHRM and organisational performance, arguing that HUC, or some part of HUC, has mediate roles in the relationship between SHRM and organisational performance in Western countries. However, little systematic research has focused on the development of a holistic overview of connections among SHRM practices, HUC and organisational performance both in Western countries and in the Chinese context. Moreover, although some research has been conducted in non-Western countries like Malaysia and Taiwan (Ahmed, Rafiq \& Saad, 2003; Yang \& Lin, 2009), the extant literature tends to be largely Western-centric.

Since Western countries and mainland China are in different stages of development and have different cultures, the mechanism between SHRM and organisational performance in the Western context and in the context of China might be different. Besides, the role mainland China plays in world economic development is becoming more and more important. There is a dearth of available literature on these dynamics in the People's Republic of China. Therefore, there is one strategic question challenging researchers in the management field in China, that is: What role, if any, does HUC play in linking SHRM practices to organisational performance?

\subsection{HRDCRM, HUC and organisational performance}

Research on HRDCRM emerged only very recently in China (Wang \& Peng, 2009). Scholarship has for example, focused on human resource marketing - which, to some extent, resembles HRDCRM - and its effect on organisational performance. Human resource marketing can be divided into internal and external varieties. Some scholars have studied the relationship between internal human resource marketing and organisational performance in the context of the service industry, concluding that internal human resource marketing has a positive effect on organisational performance (Hwang \& Chi, 2005). External human resource marketing assists marketing strategy's fulfilment through the use of external human resources, such as the consumer and human resources of associated enterprises (Gao, 2006). Scholarship has also studied external human resource marketing from the perspective of external potential employees, holding that an employer brand of high value will attract and retain employees (Schweitzer \& Lyons, 2008).

Although compelling theoretical arguments have been made in favour of human resource marketing, there is relatively weak empirical support for these approaches. Compared with human resource marketing, HRDCRM takes both internal employees and external stakeholders into account. Extant articles have shown that HUC has mediated effects on the relationship between SHRM practices and organisational performance (Youndt \& Snell, 2004), and have also shown that HUC has mediate effects on the relationship between human resource practices and department performance. That might also hold true for the relationship between HRDCRM and organisational performance. Based on the above, a conceptual model of the effect of the mechanism of HRDCRM on organisational performance has been established (see Figure 1).

\section{Theory and hypotheses}

According to Wang (2013), the factors of HRDCRM are composed of the internal marketing mix (IMM), strategic countermeasure ability (SCA), organisational attractiveness (OA), the regulatory 
mechanism (RM), sustainable business philosophy (SBP) and client orientation (CO). As stated above, the two parts of organisational performance are NPP and BFP.

Figure 1

Conceptual model

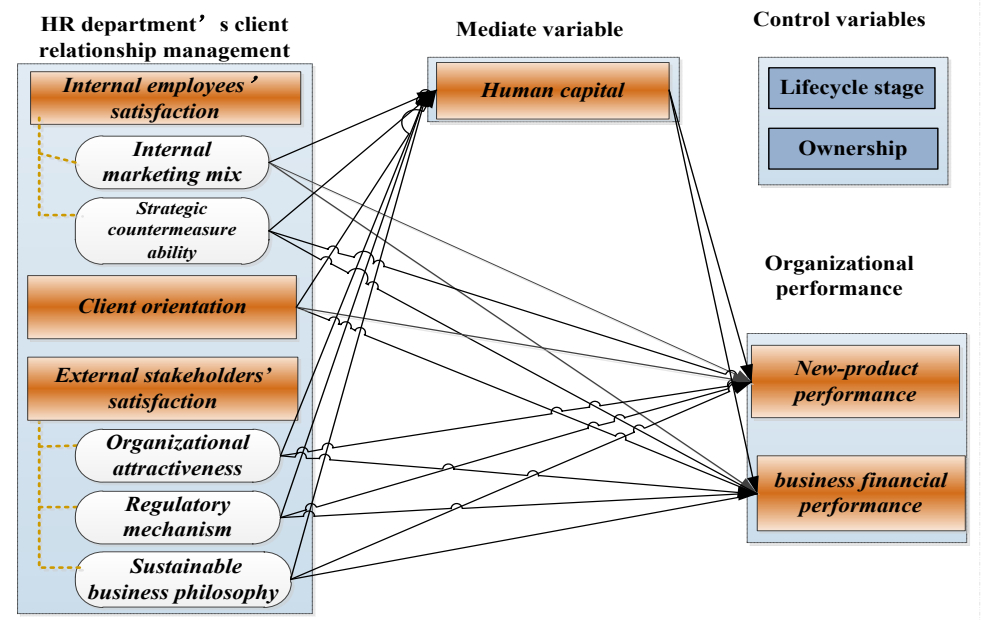

\subsection{Internal employees' satisfaction and organisational performance}

Internal employees consist of line staff, line managers, middle managers and strategic decision makers in the organisation. "Internal employees' satisfaction" refers to the satisfaction of internal employees after comparing the received service from the HR department with prior expectations. The factors of HRDCRM from the perspective of internal employees' satisfaction are composed of IMM and SCA.

\subsubsection{Internal marketing mix, HUC and organisational performance}

Internal marketing is used as a philosophy for managing the organisation's human resources based on a marketing perspective of building internal competencies for external success. IMM is concerned with employee recruitment, training, motivation, communication, and retention efforts (Guo, 2008). By integrating the marketing method into human resource management, training employees in customer orientation and high-value service, and motivating employees to observe business strategy, IMM aims at customer satisfaction and organisation development (Punjaisri \& Wilson, 2011). In Malaysia, research findings demonstrate that internal marketing is strongly related to business performance (Ahmed, Rafiq \& Saad, 2003). In China, research findings reveal that internal marketing has positive effects on frontline service employees' performance (Wang, Cong \& Yan, 2008). Given the above discussion, hypotheses from H1a to H1b are formulated:

Hla: HUC mediates the effect of the internal marketing mix (IMM) on new-product performance (NPP).

H1b: HUC mediates the effect of IMM on business financial performance (BFP).

\subsubsection{Strategic countermeasure ability, HUC and organisational performance}

"Strategic countermeasure ability" refers to the various kinds of service skills through which HR departments can deal with emergencies and assist strategic decision makers in adjusting business strategies. If HR departments can assist strategic decision makers in establishing business strategy and can cooperate with other departments of the organisation, the regulations and strategy developed by HR departments will reflect the business strategy well and will be easily accepted by employees (HUC), which will improve organisational performance (Huselid \& Becker, 2011). Skaggs and Youndt (2004) testify to the relationships between strategic positioning choices and 
HUC, and also find that certain combinations of strategic positioning and HUC result in superior performance. Therefore, we propose:

H2a: HUC mediates the effect of strategic countermeasure ability (SCA) on NPP.

H2b: HUC mediates the effect of SCA on BFP.

\subsection{External stakeholders' satisfaction and organisational performance}

External stakeholders are composed of potential employees, customers, governments, and nonprofit organisations. The factors of HRDCRM from the perspective of external stakeholders' satisfaction consist of OA, RM and SBP.

\subsubsection{Organisational attractiveness, HUC and organisational performance}

Attracting high-quality applicants (HUC) is a crucial activity for the success of an organisation (Schweitzer \& Lyons, 2008). A strong organisational attractiveness will attract more highly talented applicants (HUC). If the applicants are very knowledgeable and innovative, there might be great new-product performance, which might lead to financial gains. Therefore, we propose:

$H 3 a$ : HUC mediates the effect of organisational attractiveness $(O A)$ on NPP.

H3b: HUC mediates the effect of OA on BFP.

\subsubsection{Regulatory mechanism, HUC and organisational performance}

The regulatory mechanism is established by the HR department to act as an ombudsman. HR departments have been conceptualised as the "organisation guardian", supervising and controlling organisation management so as to make employees observe laws and regulations and avoid amoral actions (Wright \& Snell, 2005). Socially responsible international human resource management (SRIHRM) is concerned with the interests and rights of internal employees (HUC) and external stakeholders in the international setting in order to achieve long-term sustainability (Shen, 2011). Given the above, hypotheses from $\mathrm{H} 4 \mathrm{a}$ to $\mathrm{H} 4 \mathrm{~b}$ are formulated:

H4a: HUC mediates the effect of the regulatory mechanism (RM) on NPP.

$H 4 b$ : HUC mediates the effect of RM on BFP.

\subsubsection{Sustainable business philosophy, HUC and organisational performance}

"Sustainable business philosophy" refers to the HR department's endeavours with regard to green business, green consuming, and training learning consumers (HUC). This is seen to assist the image and strengthen social-citizenship behaviours. The economy in China has been developing at an astonishing speed over the past decades, which, at the same time, has brought about many serious environmental problems. As a result of the steps taken by Western developed countries, the theory of the enterprise's sustainable development has gained some attention from Chinese scholars (Cheng, Feng \& Wang, 2010; Chen \& Tang, 2006). Integrating sustainable business philosophy into the policy of the HR department will advance employees' sense of environmental protection (HUC) and may lead to an improvement in business financial performance in the long run. Therefore, we propose:

H5a: HUC mediates the effect of sustainable business philosophy (SBP) on NPP.

H5b: HUC mediates the effect of SBP on BFP.

\subsection{Client orientation, HUC and organisational performance}

"Client orientation" refers to the capacity of HR departments to meet clients' demand and increase clients' value. Client orientation is deduced from customer orientation in marketing theory. Brockman, Jones and Becherer (2012) examined the customer orientation-performance relationship among 180 small firms and the results supported the overall positive influence of customer orientation on performance. Client orientation philosophy will make the HR department shoulder its responsibility towards its clients (HUC), provide more choices for its clients, and act 
in accordance with its clients' needs (HUC). Given the above discussion, hypotheses from H6a to $\mathrm{H} 6 \mathrm{~b}$ are formulated:

H6a: HUC mediates the effect of client orientation (CO) on NPP.

H6b: HUC mediates the effect of $C O$ on BFP.

\subsection{Effects of firm-ownership and the life cycle stage}

There is substantial variation in the way human resources are managed among different ownership types, industries and regions in the People's Republic of China (Ding, Akhtar \& Ge, 2006; Zhu \& Warner, 2004). The impact of HRM also is likely to differ among different firms. Law, Tse and Zhou (2003) found that ownership types moderate the HRM-performance relationship, in that the relationship is positive and significant for joint ventures, but not for state-owned enterprises. Rutherford, Buller \& McMullen (2003) have examined the manner in which HR problems vary over the organisational life cycle. An organisation in depressed periods may care little about HRM practice, while an organisation in development periods may pay much attention to HRM practice. Therefore, this study will use ownership types and life cycle stages as control variables.

\section{Research methods}

\subsection{Data collection}

The data for this study were collected through a survey conducted among CEOs, middle and line managers, and line staff in 260 Chinese enterprises with a proportion of 10 per cent, 25 per cent, 30 per cent, and 35 per cent, respectively. In order to make our sample have a high representivity, we tried to send out questionnaires to enterprises in many different regions of the People's Republic of China (i.e. Beijing, Shanghai, Jiangsu, Shandong, Zhejiang, Sichuan, Guangxi and Tianjin). There was one questionnaire sent to each enterprise. To ensure the high reliability and recovery rate of questionnaires, we mostly selected CEOs and middle managers in smaller-scale enterprises, and line managers and line staff in larger-scale enterprises as individuals. Selecting different levels of individuals was beneficial in order to obtain different viewpoints of different clients of the HR department, which was the main purpose of the paper. A total of 260 questionnaires were distributed, with 173 questionnaires being returned (a response rate of 63.8 per cent). Of the 173 questionnaires, 166 were effective. The enterprises in the sample were randomly selected from those registered with the local government. Ownership distribution of sample enterprises is as follows: 42 enterprises are state-owned, 60 enterprises are privately owned, 36 enterprises are funded foreign holdings, 18 enterprises are funded national holdings, and 10 enterprises are others. Life cycle stage distribution of sample enterprises is composed of start-up period, growth, maturity and decline, with the proportion of 6 per cent, 41 per cent, 51.8 per cent, and 1.2 per cent, respectively.

\subsection{Measures}

\subsubsection{Dependent variables}

Most researchers regard financial performance and product market performance as important parts for measuring organisational performance (Richard et al., 2009; Jiang \& Zhao, 2006; Akhtar, Ding $\& \mathrm{Ge}, 2008)$. Some researchers also introduce other aspects in order to measure organisational performance, such as shareholder return and operational performance (Subramony, 2009). Although absolute financial performance might strengthen the research reliability, it is very difficult to find an enterprise's absolute financial performance in mainland China. Research findings show that enterprise's absolute financial performance is significantly related to relative financial performance (Jiang \& Zhao, 2006). Therefore, extant articles on the empirical study of organisational performance in mainland China often use relative financial performance. Based on the above, a measuring scale of organisational performance, including nine items and two 
dimensions (NPP and BFP), was established. All these items were measured using a five-point scale of severity from $1=$ very low to $5=$ very high. Refer to the Appendix for question items.

\subsubsection{Independent variables}

\subsubsection{Internal marketing mix}

Hwang and Chi (2005) use six indicators to measure IMM. Keller, Lynch, Ellinger, Ozment, \& Calantone, (2006), and Wang, Cong and Yan (2008) use four aspects to measure IMM. Based on the above, a measuring scale in respect of IMM, including 19 items and four dimensions, has been established. All the items are measured using a five-point scale of severity from $1=$ strongly disagree to $5=$ strongly agree. Refer to the Appendix for question items.

\subsubsection{Strategic countermeasure ability}

Literature on SCA is scarce (an exception being Jiang, Zhao \& Dai, 2010). Based on Wang, et al. (2010), combined with Wang (2013), a measuring scale for SCA, including nine items and three dimensions (assisting strategy making, strengthening departments' cooperation, and strategic positioning of the HR department), has been developed. All the items are measured using a fivepoint scale of severity from $1=$ strongly disagree to $5=$ strongly agree. All the question items can be found in the Appendix.

\subsubsection{Organisational attractiveness}

Williamson King, Lepak \& Sarma (2010) put forward three aspects affecting prospective applicants' perceptions of recruiting organisations. Berthon, Ewing and Hah (2005) use five aspects to assess organisational attractiveness. Backhaus (2004) summarises some aspects affecting OA. Based on the above, a measuring scale for OA, including five items, is established, which can be seen in the Appendix. All these items are measured using a five-point scale of severity from $1=$ strongly disagree to $5=$ strongly agree.

\subsubsection{Regulatory mechanism}

Some scholars have studied RM on a qualitative basis (Wright \& Snell, 2005), but their studies lack measuring-scale establishment. Based on Shen, Netto and Tang (2010), combined with Wang (2013), a measuring scale for RM, including five items and two dimensions, is developed. Refer to the Appendix for question items. All items are measured using a five-point scale.

\subsubsection{Sustainable business philosophy}

Research on the scale of SBP is scarce. Few articles have studied the definition and elements of SBP (Wang, Peng \& Hou 2010). Using former definitions, combined with Wang (2013), a measuring scale for SBP has been developed. The scale contains five items. All these items are measured using a five-point scale of severity from $1=$ strongly disagree to $5=$ strongly agree, which can be found in the Appendix.

\subsubsection{Client orientation}

$\mathrm{CO}$ is to some extent similar to customer orientation. Chang and Huang (2011) use a scale of nine items and three dimensions to measure customer orientation. Based on the above, a measuring scale for $\mathrm{CO}$, including five items, has been established. All these items are measured using a five-point scale of severity from $1=$ strongly disagree to $5=$ strongly agree, which can be found in the Appendix.

\subsubsection{Mediate variable}

Wright and McMahan (2011) summarise three major types of measurement of human capital (HUC), including subjective, proxy and direct assessment measures, and state that subjective measures of HUC seem to dominate the strategic HRM literature. Wang, Peng and Hou (2010) use four indexes to measure HUC. Therefore, a measuring scale for HUC, including four items, is established. All items are measured using a five-point scale. Refer to the Appendix for question items. 


\subsubsection{Control variables}

We take ownership and life cycle stage as two control variables. By referring to Wang (2010), we classify organisation ownership into five types, namely state-owned, privately owned, funded foreign holdings, funded national holdings, and others, denoted by $1,2,3,4$, and 5 , respectively By referring to Liang (2008), we classify life cycle stage into four periods, namely start-up period, growth, maturity, and decline, denoted by 1,2,3, and 4, respectively.

\section{Results}

Based on SPSS 19.0 factor analysis and reliability analysis, Cronbach's Alpha and KMO of different variables have been found, which are shown in Table 1. All the Cronbach's Alpha of different variables are $\geqq 0.840$, and most of the KMO of different variables are $\geqq 0.800$. Therefore, we can conclude that the measuring scale used in this paper is of high reliability and validity.

Table 1

Cronbach's $\alpha$ and KMO of variables

\begin{tabular}{|l|l|c|c|c|}
\hline Variables name & \multicolumn{1}{|c|}{ Definition } & Cronbach's $\alpha$ & KMO & Number of items \\
\hline IMM & Internal marketing mix & .942 & .886 & 19 \\
\hline SCA & Strategic countermeasure ability & .928 & .869 & 9 \\
\hline OA & Organisational attractiveness & .927 & .869 & 5 \\
\hline RM & Regulatory mechanism & .887 & .803 & 5 \\
\hline SBP & Sustainable business philosophy & .917 & .882 & 5 \\
\hline CO & Client orientation & .942 & .903 & 5 \\
\hline NPP & New-product performance & .840 & .724 & 3 \\
\hline BFP & Business financial performance & .968 & .892 & 6 \\
\hline HUC & Human capital & .865 & .805 & 4 \\
\hline
\end{tabular}

Table 2 shows descriptive statistics and the correlation coefficients of variables in the study. From the means and S.D., we can find that the data distribution accords with the normal distribution. In addition, none of the variables have correlation coefficients above 0.9 , and most of the variables have correlation coefficients below 0.75 , which implies that the differentiation of index is good (Peng et al., 2011). Therefore, the data can be used to conduct regression analyses. In order to test the mediate effect of HUC on the relationship between factors of HRDCRM and two parts of organisational performance, we will use the steps of Baron and Kenny (1986).

Table 2

Descriptive statistics and correlations

\begin{tabular}{|c|c|c|c|c|c|c|c|c|c|c|c|c|c|}
\hline name & Mean & S.D. & 1 & 2 & 3 & 4 & 5 & 6 & 7 & 8 & 9 & 10 & 11 \\
\hline IMM & 5377 & 0.6372 & 1 & $.783^{* \star}$ & $.710^{* \star}$ & $.706^{* *}$ & $.711^{* *}$ & $.730^{\star \star}$ & $.474^{\star *}$ & $.421^{* *}$ & .031 & .000 & $.711^{* *}$ \\
\hline SCA & 6649 & 7583 & $.783^{* \star}$ & 1 & $.853^{* *}$ & $.817^{* *}$ & $.793^{* *}$ & $.835^{\star \star}$ & $.531^{\star \star}$ & $.518^{* *}$ & .028 & 036 & $729^{\star \star}$ \\
\hline $\mathrm{OA}$ & 3349 & 0.8961 & $.710^{* *}$ & $.853^{* *}$ & 1 & $.845^{\star *}$ & $807^{* *}$ & $.835^{\star *}$ & $.578^{\star \star}$ & $.574^{* *}$ & .044 & .052 & $.783^{* *}$ \\
\hline RM & 3.5462 & 0.8139 & $.706^{\star *}$ & $.817^{\star \star}$ & $.845^{\star \star}$ & 1 & $.897^{\star *}$ & $.796^{\star \star}$ & $.570^{\star \star}$ & $.540^{* *}$ & .061 & .010 & $.788^{* *}$ \\
\hline SBP & 3.4699 & 0.8952 & $.711^{\star \star}$ & $.793^{\star \star}$ & $.807^{* *}$ & $.897^{* \star}$ & 1 & $840^{\star *}$ & $.528^{\star *}$ & $.558^{* \star}$ & .045 & -.017 & $.716^{\star *}$ \\
\hline $\mathrm{CO}$ & 3.5470 & 0.8939 & $.730^{* *}$ & $.835^{\star \star}$ & $.835^{\star \star}$ & $.796^{* *}$ & $840^{* *}$ & 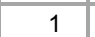 & $.513^{\star *}$ & $.517^{* *}$ & -.017 & .033 & $.752^{* *}$ \\
\hline NPP & 4297 & 0.7794 & $.474^{\star *}$ & $.531^{\star \star}$ & $.578^{\star \star}$ & $.570^{\star *}$ & $.528^{\star *}$ & $.513^{\star \star}$ & 1 & $.884^{\star \star}$ & .056 & .057 & $.691^{\star *}$ \\
\hline BFP & 3.5105 & 0.772 & $.421^{\star \star}$ & $.518^{\star \star}$ & $.574^{\star \star}$ & $.540^{* \star}$ & $.558^{* *}$ & $.517^{\star \star}$ & $.884^{\star *}$ & 1 & .055 & .046 & $.624^{* *}$ \\
\hline OWNER & 2.3614 & 1.1503 & $.031 \mathrm{~b}$ & .028 & .044 & .061 & .045 & -.017 & .056 & .055 & 1 & $-.643^{\star *}$ & .009 \\
\hline LIFE CYCLE & 2.4819 & 0.6298 & .000 & .036 & .052 & .010 & -.017 & .033 & .057 & .046 & $-.643^{* *}$ & 1 & .034 \\
\hline HUC & 3.5482 & 0.6836 & $.711^{* *}$ & $.729^{* \star}$ & $.783^{* *}$ & $.788^{* *}$ & $716^{* *}$ & $.752^{* *}$ & $.691^{* *}$ & $.624^{* *}$ & 009 & .034 & 1 \\
\hline
\end{tabular}

${ }^{* *}$ Correlation is significant at the 0.01 level (2-tailed)

Firstly, the control variables (OWNERSHIP and LIFE CYCLE) are entered in model $1^{\mathrm{b}}$ of Tables 3 and 4 respectively. Secondly, controlling the variables of enterprise ownership and life cycle stage, a series of regression models is estimated to test the mediate effect of HUC on the relationship between factors of HRDCRM (i.e. IMM, SCA, OA, RM, SBP, and CO) and NPP, and the regression results are shown in Table 3 . Thirdly, controlling the variables of enterprise ownership and life 
cycle stage, a series of regression models is estimated to test the mediate effect of HUC on the relationship between factors of HRDCRM and BFP, and the regression results are shown in Table 4 .

Table 3

Regression results

\begin{tabular}{|c|c|c|c|c|c|c|c|c|c|c|c|c|}
\hline \multirow[b]{2}{*}{$\begin{array}{c}\text { Variable } \\
\text { name }\end{array}$} & \multicolumn{7}{|c|}{ Independent variables } & \multicolumn{5}{|c|}{ Control variables } \\
\hline & IMM & SCA & OA & RM & SBP & $\mathrm{CO}$ & HUC & $\begin{array}{l}\text { OWNER- } \\
\text { SHIP }\end{array}$ & $\begin{array}{c}\text { LIFE } \\
\text { CYCLE }\end{array}$ & F statistic & $\begin{array}{c}\mathbf{R} \\
\text { square }\end{array}$ & $\begin{array}{l}\text { Adjusted } \\
\mathrm{R} \text { square }\end{array}$ \\
\hline Model $1^{\mathrm{b}}$ & & & & & & & & 0.052 & 0.067 & 0.220 & 0.003 & -0.010 \\
\hline Model 1, b & & & & & & & $0.691^{* \star \star}$ & 0.050 & 0.034 & $149.651^{\star \star \star}$ & 0.477 & 0.474 \\
\hline Model $2^{\mathrm{a}}$ & $0.711^{\star * *}$ & & & & & & & -0.013 & 0.034 & $168.084^{* * *}$ & 0.506 & 0.503 \\
\hline Model $3^{b}$ & $0.474^{\star \star \star}$ & & & & & & & 0.041 & 0.057 & $47.408^{\star \star \star}$ & 0.224 & 0.220 \\
\hline Model $4^{b}$ & -0.036 & & & & & & $0.691^{* * *}$ & 0.050 & 0.034 & $149.651^{* * *}$ & 0.477 & 0.474 \\
\hline Model $5^{\mathrm{a}}$ & & $0.729^{* * *}$ & & & & & & -0.012 & 0.008 & $185.49^{* \star *}$ & 0.329 & 0.325 \\
\hline Model $6^{b}$ & & $0.531^{\text {***}}$ & & & & & & 0.041 & 0.038 & $64.379^{* * *}$ & 0.282 & 0.278 \\
\hline Model $7^{\mathrm{b}}$ & & 0.059 & & & & & $0.691^{* \star \star}$ & 0.050 & 0.034 & $149.651^{* \star *}$ & 0.477 & 0.474 \\
\hline Model $8^{a}$ & & & $0.783^{\star \star \star}$ & & & & & -0.026 & -0.007 & $259.424^{\star \star \star}$ & 0.613 & 0.610 \\
\hline Model $9^{b}$ & & & $0.578^{\star \star *}$ & & & & & 0.030 & 0.027 & $82.391^{\star \star \star}$ & 0.334 & 0.330 \\
\hline Model $10^{b}$ & & & 0.097 & & & & $0.691^{\text {*** }}$ & 0.050 & 0.034 & $149.651^{* * *}$ & 0.477 & 0.474 \\
\hline Model $11^{a}$ & & & & $0.788^{\star * *}$ & & & & -0.040 & 0.026 & $268.466^{* * *}$ & 0.621 & 0.618 \\
\hline Model $12^{b}$ & & & & $0.570^{\star * *}$ & & & & 0.021 & 0.052 & $79.085^{\star \star \star}$ & 0.325 & 0.321 \\
\hline Model $13^{b}$ & & & & 0.069 & & & $0.691^{\text {*** }}$ & 0.050 & 0.034 & $149.651^{* * *}$ & 0.477 & 0.474 \\
\hline Model $14^{a}$ & & & & & $0.716^{\star \star \star}$ & & & -0.024 & 0.046 & $172.909^{* \star \star}$ & 0.513 & 0.510 \\
\hline Model $15^{b}$ & & & & & $0.528^{\star \star \star}$ & & & 0.032 & 0.066 & $63.283^{\star \star \star}$ & 0.278 & 0.274 \\
\hline Model $16^{b}$ & & & & & 0.067 & & $0.691^{* * *}$ & 0.050 & 0.034 & $149.651^{* * *}$ & 0.477 & 0.474 \\
\hline Model $17^{a}$ & & & & & & $0.752^{* * *}$ & & 0.021 & 0.009 & $213.394^{* * *}$ & 0.565 & 0.563 \\
\hline Model $18^{b}$ & & & & & & $0.513^{\star * *}$ & & 0.064 & 0.040 & $58.59^{* * *}$ & 0.263 & 0.259 \\
\hline Model19 ${ }^{b}$ & & & & & & -0.015 & $0.691^{\text {*** }}$ & 0.050 & 0.034 & $149.651^{* * *}$ & 0.477 & 0.474 \\
\hline
\end{tabular}

Notes: ${ }^{*} P<0.1 ;{ }^{*} P<0.05 ;{ }^{* * *} P<0.01$ (two-tailed test). $N=166$; a: dependent variable, HUC; $b$ : dependent variable, NPP

Table 4

Regression results

\begin{tabular}{|c|c|c|c|c|c|c|c|c|c|c|c|c|}
\hline \multirow{2}{*}{$\begin{array}{c}\text { Variable } \\
\text { name }\end{array}$} & \multicolumn{7}{|c|}{ Independent variables } & \multicolumn{5}{|c|}{ Control variables } \\
\hline & IMM & SCA & OA & RM & SBP & co & HUC & $\begin{array}{l}\text { OWNER } \\
\text {-SHIP }\end{array}$ & $\begin{array}{c}\text { LIFE } \\
\text { CYCLE }\end{array}$ & F statistic & $\begin{array}{c}\mathbf{R} \\
\text { square }\end{array}$ & $\begin{array}{l}\text { Adjusted } \\
\text { R square }\end{array}$ \\
\hline Model $1^{\mathrm{b}}$ & & & & & & & & 0.145 & 0.139 & 1.184 & 0.014 & 0.002 \\
\hline Model 1, b & & & & & & & $0.624^{\star \star *}$ & 0.050 & 0.025 & $104.470^{\star \star *}$ & 0.389 & 0.385 \\
\hline Model $2^{a}$ & $0.711^{* * *}$ & & & & & & & -0.013 & 0.034 & $168.084^{* * *}$ & 0.506 & 0.503 \\
\hline Model $3^{b}$ & $0.421 * * *$ & & & & & & & 0.042 & 0.046 & $35.383^{\star \star *}$ & 0.177 & 0.172 \\
\hline Model $4^{b}$ & -0.046 & & & & & & $0.624^{\star \star *}$ & 0.050 & 0.025 & $104.470^{* \star *}$ & 0.389 & 0.385 \\
\hline Model $5^{a}$ & & $0.729^{\star \star \star}$ & & & & & & -0.012 & 0.008 & $185.49^{\star \star \star}$ & 0.329 & 0.325 \\
\hline Model $6^{\mathrm{b}}$ & & $0.518^{* * *}$ & & & & & & 0.041 & 0.027 & $60.066^{\star \star *}$ & 0.268 & 0.264 \\
\hline Model $7^{\mathrm{b}}$ & & 0.135 & & & & & $0.624^{\star \star *}$ & 0.050 & 0.025 & $104.470^{* * *}$ & 0.389 & 0.385 \\
\hline Model $8^{a}$ & & & $0.783^{* * *}$ & & & & & -0.026 & -0.007 & $259.424^{* * *}$ & 0.613 & 0.610 \\
\hline Model $9^{b}$ & & & $0.574^{\star \star *}$ & & & & & 0.030 & 0.016 & $80.424^{\star \star \star}$ & 0.329 & 0.325 \\
\hline Model $10^{\mathrm{D}}$ & & & $0.220^{\star \star}$ & & & & $0.451^{\star \star *}$ & 0.042 & 0.019 & $56.154^{\star \star *}$ & 0.408 & 0.401 \\
\hline Model $11^{\mathrm{a}}$ & & & & $0.788^{* * *}$ & & & & -0.040 & 0.026 & $268.466^{* * *}$ & 0.621 & 0.618 \\
\hline Model $12^{b}$ & & & & $0.540 * * *$ & & & & 0.022 & 0.040 & $67.522 * * *$ & 0.292 & 0.287 \\
\hline Model $13^{b}$ & & & & 0.128 & & & $0.624 * * *$ & 0.050 & 0.025 & $104.470^{* * *}$ & 0.389 & 0.385 \\
\hline Model $14^{a}$ & & & & & $0.716^{* * *}$ & & & -0.024 & 0.046 & $172.909 * * *$ & 0.513 & 0.510 \\
\hline Model $15^{b}$ & & & & & $0.558^{* * *}$ & & & 0.030 & 0.055 & $74.023^{* * *}$ & 0.311 & 0.307 \\
\hline Model $16^{b}$ & & & & & $0.228^{* * *}$ & & $0.461 * * *$ & 0.041 & 0.034 & $57.659 * * *$ & 0.414 & 0.407 \\
\hline Model $17^{\mathrm{a}}$ & & & & & & $0.752 * * *$ & & 0.021 & 0.009 & $213.394^{* * *}$ & 0.565 & 0.563 \\
\hline Model $18^{b}$ & & & & & & $0.517 * * *$ & & 0.064 & 0.029 & $59.934 * * *$ & 0.268 & 0.263 \\
\hline Model19b & & & & & & 0.111 & $0.624 * * *$ & 0.050 & 0.025 & $104.470^{* * *}$ & 0.389 & 0.385 \\
\hline
\end{tabular}

Notes: ${ }^{*} P<0.1 ;{ }^{*} P<0.05 ;{ }^{* * *} P<0.01$ (two-tailed test). $N=166$; a: dependent variable, HUC; $b$ : dependent variable, BFP 


\subsection{Mediate effects of HUC on the relationship between HIRDCRM and NPP}

In Table 3, controlling the variables of enterprise ownership and life cycle stage, the results in model $1^{\text {, }}$ indicate that HUC has a significant and positive effect on NPP (Beta $\left.=.691, \mathrm{P}<0.01\right)$; the results in model $2^{\mathrm{a}}$ indicate that IMM is positively related to HUC (Beta $=0.711, \mathrm{P}<0.01$ ); the results in model $3^{\mathrm{b}}$ show that IMM is significantly related to NPP (Beta $\left.=0.474, \mathrm{P}<0.01\right)$; and the results in model $4^{\mathrm{b}}$ show that HUC has a significant and positive effect on NPP (Beta $=0.691$, $\mathrm{P}<0.01)$; while IMM shows no significant effect on NPP $(\mathrm{P}>0.1)$. According to Baron and Kenny (1986), we can conclude that HUC completely mediates the effect of IMM on NPP. Therefore, hypothesis $\mathrm{H} 1 \mathrm{a}$ is supported.

Likewise, in model $5^{\mathrm{a}}$, model $6^{\mathrm{b}}$ and model $7^{\mathrm{b}}$, the coefficient of SCA on HUC is significant $($ Beta $=0.729, \mathrm{P}<0.01)$; the coefficient of SCA on NPP is significant (Beta $=0.531, \mathrm{P}<0.01$ ); and HUC has a significant and positive effect on NPP (Beta $=0.691, \mathrm{P}<0.01$ ); while SCA shows no significant effect on NPP ( $\mathrm{P}>0.1)$. Therefore, HUC completely mediates the effect of SCA on $\mathrm{NPP}$, and hypothesis $\mathrm{H} 2 \mathrm{a}$ is supported.

In model $8^{\mathrm{a}}$, model $9^{\mathrm{b}}$ and model $10^{\mathrm{b}}$, the coefficient of OA on HUC is significant (Beta $=$ $0.783, \mathrm{P}<0.01$ ); the coefficient of OA on NPP is significant (Beta $=0.578, \mathrm{P}<0.01$ ); and HUC has a significant and positive effect on NPP $($ Beta $=0.691, \mathrm{P}<0.01)$; while OA shows no significant effect on NPP $(\mathrm{P}>0.1)$. Therefore, HUC completely mediates the effect of OA on NPP, and hypothesis H3a is supported.

In model $11^{\mathrm{a}}$, model $12^{\mathrm{b}}$ and model $13^{\mathrm{b}}$, the coefficient of RM on HUC is significant (Beta $=$ $0.788, \mathrm{P}<0.01$ ); the coefficient of RM on NPP is significant (Beta $=0.570, \mathrm{P}<0.01$ ); and $\mathrm{HUC}$ has a significant and positive effect on NPP $($ Beta $=0.691, \mathrm{P}<0.01)$; while $\mathrm{RM}$ shows no significant effect on NPP $(\mathrm{P}>0.1)$. Therefore, HUC completely mediates the effect of RM on NPP, and hypothesis $\mathrm{H} 4 \mathrm{a}$ is supported.

In model $14^{\mathrm{a}}$, model $15^{\mathrm{b}}$ and model $16^{\mathrm{b}}$, the coefficient of SBP on HUC is significant (Beta $=$ $0.716, \mathrm{P}<0.01$ ); the coefficient of SBP on NPP is significant (Beta $=0.528, \mathrm{P}<0.01$ ); and HUC has a significant and positive effect on NPP (Beta $=0.691, \mathrm{P}<0.01)$; while SBP shows no significant effect on NPP $(\mathrm{P}>0.1)$. Therefore, HUC completely mediates the effect of SBP on NPP, and hypothesis $\mathrm{H} 5 \mathrm{a}$ is supported.

In model $17^{\mathrm{a}}$, model $18^{\mathrm{b}}$ and model $19^{\mathrm{b}}$, the coefficient of $\mathrm{CO}$ on HUC is significant $($ Beta $=$ $0.752, \mathrm{P}<0.01$ ); the coefficient of $\mathrm{CO}$ on NPP is significant (Beta $=0.513, \mathrm{P}<0.01$ ); and HUC has a significant and positive effect on NPP $($ Beta $=0.691, \mathrm{P}<0.01)$; while CO shows no significant effect on NPP ( $>0.1)$. Therefore, HUC completely mediates the effect of CO on NPP, and hypothesis H6a is supported.

\subsection{Mediate effects of HUC on the relationship between HRDCRM and BFP}

With the same analysis, in Table 4 , results in model $1^{\mathrm{b}}$, model $2^{\mathrm{a}}$, model $3^{\mathrm{b}}$, and model $4^{\mathrm{b}}$ indicate that HUC is positively related to BFP (Beta $=0.624, \mathrm{P}<0.01$ ); that IMM has a significant and positive effect on HUC $($ Beta $=0.711, \mathrm{P}<0.01)$; that IMM is significantly related to $\mathrm{BFP}(\mathrm{Beta}=$ $0.421, \mathrm{P}<0.01)$; and that HUC has a significant and positive effect on $\mathrm{BFP}(\mathrm{Beta}=0.624, \mathrm{P}<0.01)$; while IMM shows no significant effect on BFP $(\mathrm{P}>0.1)$. Therefore, HUC completely mediates the effect of IMM on BFP, and hypothesis H1b is supported.

Likewise, in model $5^{\mathrm{a}}$, model $6^{\mathrm{b}}$ and model $7^{\mathrm{b}}$, the coefficient of SCA on HUC is significant $($ Beta $=0.729, \mathrm{P}<0.01)$; the coefficient of SCA on BFP is significant (Beta $=0.518, \mathrm{P}<0.01$ ); and HUC has a significant and positive effect on BFP (Beta $=0.624, \mathrm{P}<0.01)$; while SCA shows no significant effect on BFP ( $\mathrm{P}>0.1)$. Therefore, HUC completely mediates the effect of SCA on $\mathrm{BFP}$, and hypothesis $\mathrm{H} 2 \mathrm{~b}$ is supported.

In model $8^{\mathrm{a}}$, model $9^{\mathrm{b}}$ and model $10^{\mathrm{b}}$, the coefficient of OA on HUC is significant (Beta $=$ $0.783, \mathrm{P}<0.01$ ); the coefficient of $\mathrm{OA}$ on $\mathrm{BFP}$ is significant (Beta $=0.574, \mathrm{P}<0.01$ ); $\mathrm{HUC}$ has a significant and positive effect on $\mathrm{BFP}(\mathrm{Beta}=0.451, \mathrm{P}<0.01)$; and $\mathrm{OA}$ shows a significant effect on BFP $(\mathrm{P}<0.05)$. Therefore, HUC partially mediates the effect of OA on BFP and hypothesis $\mathrm{H} 3 \mathrm{~b}$ is supported. 
In model $11^{\mathrm{a}}$, model $12^{\mathrm{b}}$ and model $13^{\mathrm{b}}$, the coefficient of RM on HUC is significant (Beta $=$ $0.788, \mathrm{P}<0.01$ ); the coefficient of RM on BFP is significant (Beta $=0.540, \mathrm{P}<0.01$ ); and $\mathrm{HUC}$ has a significant and positive effect on $\mathrm{BFP}($ Beta $=0.624, \mathrm{P}<0.01)$; while $\mathrm{RM}$ shows no significant effect on BFP $(\mathrm{P}>0.1)$. Therefore, HUC completely mediates the effect of RM on BFP, and hypothesis $\mathrm{H} 4 \mathrm{~b}$ is supported.

In model $14^{\mathrm{a}}$, model $15^{\mathrm{b}}$ and model $16^{\mathrm{b}}$, the coefficient of SBP on HUC is significant (Beta $=$ $0.716, \mathrm{P}<0.01)$; the coefficient of $\mathrm{SBP}$ on $\mathrm{BFP}$ is significant $(\mathrm{Beta}=0.558, \mathrm{P}<0.01)$; HUC has a significant and positive effect on BFP $($ Beta $=0.461, \mathrm{P}<0.01)$; and SBP shows a significant effect on BFP (Beta $=0.228, \mathrm{P}<0.01)$. Therefore, HUC partially mediates the effect of SBP on BFP. and hypothesis H5b is supported.

In model $17^{\mathrm{a}}$, model $18^{\mathrm{b}}$ and model $19^{\mathrm{b}}$, the coefficient of $\mathrm{CO}$ on HUC is significant (Beta $=$ 0.752, $\mathrm{P}<0.01$ ); the coefficient of $\mathrm{CO}$ on BFP is significant (Beta $=0.517, \mathrm{P}<0.01$ ); and $\mathrm{HUC}$ has a significant and positive effect on $\mathrm{BFP}(\mathrm{Beta}=0.624, \mathrm{P}<0.01)$; while $\mathrm{CO}$ shows no significant effect on BFP $(\mathrm{P}>0.1)$. Therefore, HUC completely mediates the effect of $\mathrm{CO}$ on BFP, and hypothesis H6b is supported.

All the relevant results regarding the hypotheses have been summarised in Figure 2.

Figure 2

Mediate effects of HUC

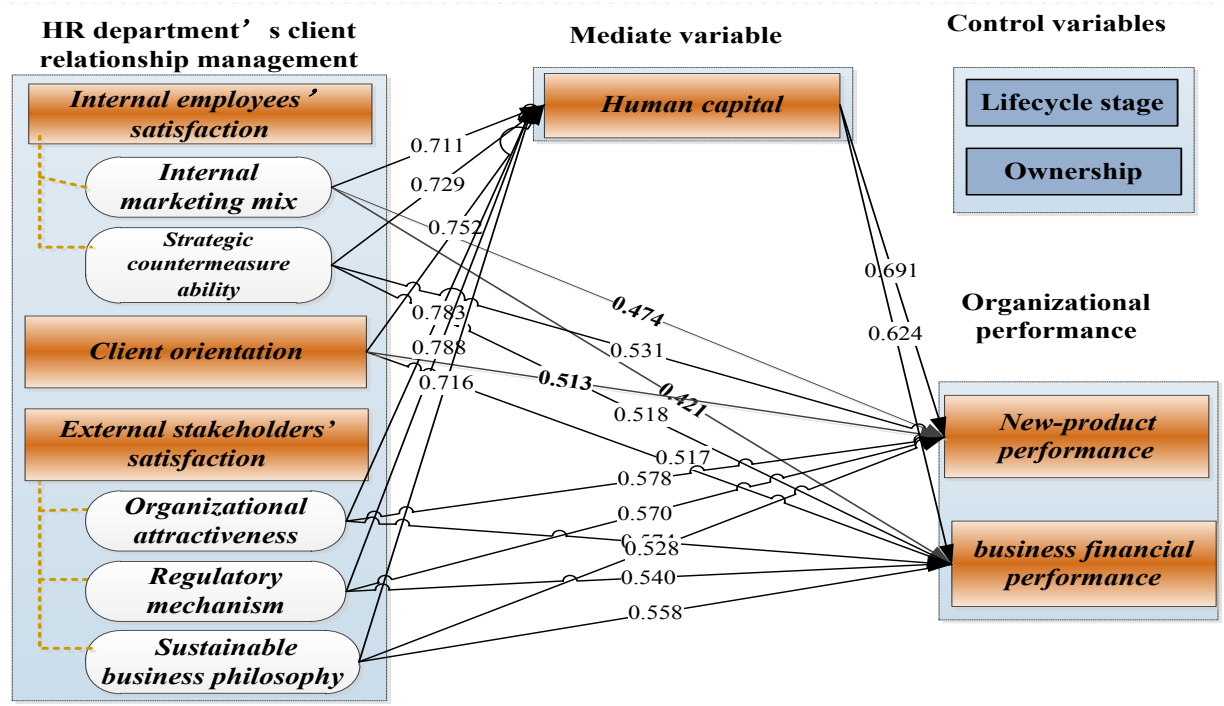

\section{Discussion}

Research findings indicate that HUC completely mediates the effect of factors of HRDCRM on NPP, that is, HRDCRM can indirectly promote an increase in new-product performance by improving organisations' HUC. The findings accord with the results of Lopez-Cabrales et al., (2009) and Yang \& Lin (2009). We also can find that HUC completely mediates the effect of IMM, SCA, RM and CO on BFP. This shows that, for the purpose of customer satisfaction and organisation development (Punjaisri \& Wilson, 2011), the HR department's endeavours in optimising the internal marketing mix will improve the value of HUC, and that an HUC of high value will bring about high organisational performance (Skaggs \& Youndt, 2004). Based on the above, we can find that, both in the Western context and in the context of China, HUC plays mediate roles in the relationship between SHRM practices and organisational performance. Therefore, in order to improve the positive impact of SHRM practices on organisational performance, enterprises both in Western countries and mainland China should focus on human 
capital accumulation and development.

In addition, we can find that the strategic countermeasure ability of an HR department, an HR department's regulatory mechanism, and client orientation-HR department's core service philosophy can indirectly improve business financial performance by enhancing the HUC of enterprises in mainland China. This finding to some extent represents Chinese characteristics. The reason for this, on the one hand, might be the culture differences between Western countries and China, and, on the other, might lie in the different stages of economic development. The economy in mainland China has been developing at an astonishing speed over the past decades, which, at the same time, has brought about many serious environmental problems. Compared with enterprises in Western countries, enterprises in China should pay more attention to aligning HUC with SHRM practices in order to realise an improvement in sustainable performance.

Research findings also indicate that HUC partially mediates the effect of OA and SBP on BFP. This means, on the one hand, that organisational attractiveness and an HR department's sustainable business philosophy can directly promote an increase in business financial performance, and, on the other, that they can indirectly improve business financial performance by building up HUC. Therefore, in order to realise the enhancement of organisational performance, Chinese firms should not only strengthen HRDCRM, but also establish a close tie between HRDCRM and HUC owned by firms. HRDCRM contributes to organisational performance, and, with the inclusion of HUC and its dimensions as a mediator, it further helps to improve organisational performance (Daud \& Yusoff, 2011).

\subsection{Managerial implications}

Our study provides several findings for Chinese firms to optimise HRM practices and improve organisational performance. Firstly, HR departments in Chinese firms should relate their function of traditional personnel administration to the firm's HUC. The essential role that HR departments play is concerned with employee recruitment, training, motivation, communication, and retention efforts (Punjaisri \& Wilson, 2011). In order to realise organisational performance advancement, the key to fulfilling the essential role of the HR department is to recruit employees of high capability; to create a work environment of communication and knowledge-sharing; to motivate employees to understand and observe business culture; and to train employees in customer orientation. Only when the HR department's essential role is in alignment with the situation in respect of HUC can organisational performance be strengthened sustainably.

Secondly, Chinese firms should align the HR department's management practices with the firm's strategy (Lengnick-Hall et al., 2009) and strengthen the strategic countermeasure ability of the HR department. The impact of the HR department's strategic countermeasure ability on an increase in organisational performance can be further advanced and mediated by HUC. If the HR department can deal with emergencies outside of the company with ease and can assist strategic decision makers in adjusting business strategies, the regulations and strategy formulated by the HR department will reflect the business strategy well. Consequently, the relationship between external stakeholders and the organisation will become harmonious, which will encourage the improvement of organisational performance. Simultaneously, strategy-oriented regulations of HR departments will attract potential employees of high value and will advance internal employees' job satisfaction, bringing about an increase in HUC. All in all, the increase in human capital will result in an improvement in organisational performance (Yang \& Lin, 2009).

Thirdly, a sound regulatory mechanism employed by the HR department will be beneficial to organisational performance advancement in the long run. While a firm might have considered only economic profit in the past, this would not have been against the background of knowledge economy. On the one hand, the environment in which we are living deteriorates, and, on the other, the quality of human resources in society increases. All these situations drive enterprises to change their business philosophy. HR departments should care more about employees' demands, social needs, and environmental responsibility (Cheng et al., 2010; Chen \& Tang, 2006). 
Fourthly, integrating sustainable business philosophy into HRM practices will stimulate enterprises to develop in a sustainable way, thereby leading to a sustainable increase in profits. To realise sustainable development with regard to the enterprise, to ensure environmental protection, and to shoulder the responsibility of social citizenship, HR departments in Chinese firms should nourish internal employees with a sense of environmental protection and should encourage their voluntary compliance with laws and regulations relating to environmental protection. In addition, the HR department should have a broad vision, should communicate with non-profit organisations, should focus on public relationships, and should care more about stakeholders' demand concerning HRM practices.

\subsection{Limitations and future research}

The results indicate several problems that deserve further scrutiny. Firstly, we tested the mediate role of HUC in the relationship between factors of HRDCRM and organisational performance. However, it may also be appropriate to approach intellectual capital from other levels of analysis. It may prove beneficial to move beyond the independent analysis of HUC in order to examine the effects of intellectual capital in the relationship between HRDCRM and organisational performance (Yang \& Lin, 2009) in future research.

Secondly, the data used in this study were mainly collected from firms located in eastern China. Of course, all the samples we used in the study were randomly selected and they had some significance in conducting the analysis of the mechanism of HRDCRM and organisational performance. It is not yet known how the collection in different geographical areas would affect the study's findings. In addition, there was a single respondent from each enterprise completing all the survey questions, which might give rise to the multi-collinearity problem and might likely to lead to statistical problems in the form of biased estimates in the regression analysis. We will revise the construct of independent variables and widen our scope of survey so as to obtain more data in future research.

Thirdly, although the data we collected were from different levels of individuals in different organisations, we did not split the data between CEOs, middle and line managers, and line staff. Different levels of individuals might have some effects in analysing the impact of HRDCRM on organisational performance. We will compare the viewpoints of different clients on the HR department's roles in future research.

Fourthly, as Chinese firms are undergoing various stages of reform, simply looking at the ownership and life cycle stage as control variables may not accurately reflect the mediate effect of human capital on the relationship between HRDCRM and organisational performance. The roles HR departments play might vary from industry to industry. Future studies should add industry type and enterprise scale to the control variables and examine their impacts.

\section{Conclusion}

HR departments' client relationship management (HRDCRM) is a growing area of interest within strategic human resource management. Based on a survey of 260 Chinese enterprises, we have made an empirical study of the mediate role of human capital in the relationship between HRDCRM and organisational performance. The findings show that the combination of HRDCRM as optimal human resource management practices and human capital as organisational strategic assets will further improve organisational performance. In order to strengthen organisational performance, besides fulfilling traditional functions and meeting the demands of internal stakeholders to cultivate human capital, HR departments of Chinese firms should act as a strategic partner, a business guardian and a social responsibility regulator and care more about external stakeholders' needs regarding HRM practices. 


\section{Acknowledgement}

This paper is funded by the National Social Science Foundation of China (Grant no. 14CGL017), the National Natural Science Foundation of China (Grant no. 71471041), the Humanities and Social Science Research Projects of the Ministry of Education of China (Grant no. 11YJC630213), and the Innovation Programme of the Shanghai Municipal Education Commission (Grant no. 12YS040).

\section{References}

AHMED, P.K., RAFIQ, M. \& SAAD, N.M. 2003. Internal marketing and the mediating role of $\begin{array}{ll}\text { organizational competencies. } & 37(9): 1221-1241 .\end{array}$

AKHTAR, S., DING, D.Z. \& GE, G.L. 2008. Strategic HRM practices and their impact on company performance in Chinese enterprises. Human Resource Management 47(1):15-32.

AUGUSTO, F.J., COUTO, E. \& CAIADO, J. 2014. Human capital, social capital and organizational performance. Management Decision 52(2):350-364.

BACKHAUS, K.B. 2004. An exploration of corporate recruitment descriptions on Monster. Journal of Business Communication 41(2):115-136.

BARON, R.M. \& KENNY, D.A. 1986. The moderator-mediator variable distinction in social psychological research: Conceptual, strategic, and statistical considerations. Journal of Personality and Social Psychology 51(6):1173-1182.

BERTHON, P., EWING, M. \& HAH, L.L. 2005. Captivating company: Dimensions of attractiveness in employer branding. International Journal of Advertising 24(2):151-178.

BROCKMAN, B.K., JONES, M.A. \& BECHERER, R.C. 2012. Customer orientation and performance in small firms: Examining the moderating influence of risk-taking, innovativeness, and opportunity focus. Journal of Small Business Management 50(3):429-446.

CHANG, W.J.A. \& HUANG, T.C. 2011. Customer orientation as a mediator of the influence of locus of control on job performance. Service Industries Journal 31(2):273-285.

CHEN, C.J. \& HUANG, J.W. 2009. Strategic human resource practices and innovation performance - the mediating role of knowledge management capacity. Journal of Business Research 6(2):104-114.

CHEN, Y. \& TANG, X.J. 2006. The research on the enterprise's sustainable growth capability and its generation mechanism. Management World (12):111-114.

CHENG, H.W., FENG, Q.Y. \& WANG, Y. 2010. The natural contract, ecological profits and firm sustainable development. China Industrial Economy (5):88-98.

DAUD, S. \& YUSOFF, W.F.W. 2011. How intellectual capital mediates the relationship between knowledge management processes and organizational performance. African Journal of Business Management 5(7):26072617.

DING, D.Z., AKHTAR, S. \& GE, L. 2006. Organizational differences in managerial compensation and benefits in Chinese firms. International Journal of Human Resource Management (17):693-715.

GAO, F. 2006. Research of recruitment based on human resource marketing. Journal of Qinghai Normal University (Philosophy and Social Sciences Edition) (1):16-18.

GUO, B. 2008. Internal marketing: A new practice of human resource management. Scientific Management Research (6):62-65.

GURBUZ, S. \& MERT, I.S. 2011. Impact of the strategic human resource management on organizational performance: Evidence from Turkey. International Journal of Human Resource Management 22(8):18031822.

HUSELID, M.A. \& BECKER, B.E. 2011. Bridging micro and macro domains: Workforce differentiation and strategic human resource management. Journal of Management 37(2):421-428.

HWANG, I.S. \& CHI, D.J. 2005. Relationships among internal marketing, employee job satisfaction and international hotel performance: An empirical study. International Journal of Management 22(2): 285-293.

JIANG, C.Y. \& ZHAO, S.M. 2006. The relationship between social capital, company enterprise and company performance: The medium role of organizational learning - a case study of the new and developing enterprises in Jiangsu and Guangdong. Management World (10):90-99.

JIANG, J.W., ZHAO, S.M. \& DAI, W.W. 2010. A study of the impact of strategic human resource management on organizational innovation. Chinese Journal of Management 7(12):1779-1784. 
KELLER, S.B., LYNCH, D.E., ELLINGER, A.E., OZMENT, J. \& CALANTONE, R.J. 2006. The impact of internal marketing efforts in distribution service operations. Journal of Business Logistics 27(1):109-137. KONG, E. \& THOMSON, S.B. 2009. An intellectual capital perspective of human resource strategies and practices. Knowledge Management Research \& Practice 7(4):356-364.

LAW, K.S., TSE, D.K. \& ZHOU, N. 2003. Does human resource management matter in a transitional economy? China as an example. Journal of International Business Studies (34):255-265.

LENGNICK-HALL, M.L., LENGNICK-HALL, C.A., ANDRADE, L.S. \& DRAKE, B. 2009. Strategic human resource management: The evolution of the field. Human Resource Management Review 19(2):64-85. LIANG, H.S. 2008. Study on the mechanism of organizational innovation factor based on enterprise's lifecycle stage. Unpublished PhD dissertation, Harbin Institute of Technology.

LOPEZ-CABRALES, A., PÉREZ-LUÑO, A. \& CABRERA, R.V. 2009. Knowledge as a mediator between HRM practices and innovative activity. Human Resource Management 48(4):485-503.

PENG, Z.L.,WANG, H.H. \& JIANG, X.C. 2011. Effect of Resource Sharing on Innovation Performance under the Open Innovation Model: the Mediating Effect of Knowledge Transfer. Science of Science and Management of S.\&T., 32(1):48-53.

PUNJAISRI, K. \& WILSON, A. 2011. Internal branding process: Key mechanisms, outcomes and moderating factors. European Journal of Marketing 45(9\10):1521-1537.

RICHARD, P.J., DEVINNEY, T.M., YIP, G.S. \& JOHNSON, G. 2009. Measuring organizational performance: Towards methodological best practice. Journal of Management 35(3):718-804.

RUTHERFORD, M.W., BULLER, P.F. \& McMULLEN, P.R. 2003. Human resource management problems over the life cycle of small to medium-sized firms. Human Resource Management 42(4):321-335.

SCHWEITZER, L. \& LYONS, S. 2008. The market within: A marketing approach to creating and developing high-value employment relationships. Business Horizons 51(6):555-565.

SHEN, J. 2011. Developing the concept of socially responsible international human resource management. International Journal of Human Resource Management 22(6):1351-1363.

SHEN, J., NETTO, B.D. \& TANG, J. 2010. Effects of human resource diversity management on organizational citizen behavior in the Chinese context. International Journal of Human Resource Management 21(12):2156-2172.

SKAGGS, B.C. \& YOUNDT, M. 2004. Strategic positioning, human capital, and performance in service organizations: A customer interaction approach. Strategic Management Journal 25(1):85-99.

SUBRAMONY, M.A. 2009. Meta-analytic investigation of the relationship between HRM bundles and firm performance. Human Resource Management 48(5):745-768.

ULRICH, D., YOUNGER, J. \& BROCKBANK, W. 2008. The twenty-first-century HR organization. Human Resource Management 47(4):829-850.

WANG, X.L. 2013. Study on factors affecting HR department's client relationship management based on grounded theory. Soft Science 27(6):98-102, 113.

WANG, Z.W. 2010.Study on the influential mechanism of enterprises' external knowledge network on disruptive innovation performance. Unpublished doctoral dissertation, Zhejiang University, China.

WANG, Y.M., CONG, Q. \& YAN, H. 2008. An empirical study on the effect of internal marketing on frontline service employees' performance. Nankai Business Review (6):28-36.

WANG, X.L. \& PENG, Z.L. 2009. The research on human resource department's client relationship management. East China Economic Management 23(9):81-87.

WANG, X.L., PENG, Z.L. \& HOU, Y.Z. 2010. The research on the relationship between HR department's client relationship management and intellectual capital. Science and Technology Management Research (9):134-137,141.

WILLIAMSON, I.O., KING, J.E., LEPAK, D. \& SARMA, A. 2010. Firm reputation, recruitment web sites, and attracting applicants. Human Resource Management -687 .

WRIGHT, P.M. \& McMAHAN, G.C. 2011. Exploring human capital: Putting human back into strategic human resource management. Human Resource Management Journal 21(2):93-104.

WRIGHT, P.M. \& SNELL, S.A. 2005. Partner or guardian? HR's challenge in balancing value and values. Human Resource Management 44(2):177-182. 
YANG, C.C. \& LIN, C.Y.Y. 2009. Does intellectual capital mediate the relationship between HRM and organizational performance? Perspective of a healthcare industry in Taiwan. The International Journal of Human Resource Management 20(9):1965-1984.

YOUNDT, M.A. \& SNELL, S.A. 2004. Human resource configurations, intellectual capital, and organizational performance. Journal of Managerial Issues $\quad-360$.

ZHU, Y. \& WARNER, M. 2004. Changing patterns of human resource management in contemporary China: WTO accession and enterprise responses. Industrial Relations Journal (35):311-328.

\section{Appendix}

\section{Question items}

\section{Factors of HR department's client relationship management}

\section{Internal marketing mix (IMM)}

\begin{tabular}{|c|c|}
\hline \multirow{5}{*}{$\begin{array}{l}\text { Internal job } \\
\text { product }\end{array}$} & 1. The HR department cares about my welfare. \\
\hline & 2. My supervisor and colleagues admire and respect me. \\
\hline & 3. The HR department will tell me how to work, and why. \\
\hline & 4. My supervisor and colleagues will let me know when I have done a great job. \\
\hline & 5. I have been given a work environment beneficial to my career development. \\
\hline \multirow{4}{*}{ Internal price } & 6. The HR department often spends some time answering my questions. \\
\hline & 7. The HR department helps me to solve my problems actively. \\
\hline & 8. My supervisor and the HR department will give me feedback on my demands and complaints in time. \\
\hline & 9. My supervisor and the HR department will supply me with essential information quickly. \\
\hline \multirow{5}{*}{ Internal place } & 10. My supervisor and colleagues often discuss my work problems with me in private. \\
\hline & 11. My colleagues and I often communicate with one another freely. \\
\hline & 12. My supervisor and colleagues often share their work happiness with me. \\
\hline & 13. We have good information-sharing. \\
\hline & 14. The HR department has established an effective information feedback system. \\
\hline \multirow{5}{*}{$\begin{array}{l}\text { Internal } \\
\text { promotion }\end{array}$} & 15. The HR department has established a fair work atmosphere. \\
\hline & 16. The HR department provides me with a harmonious work environment. \\
\hline & 17. My supervisor and colleagues let me know that they will assist me when I need help. \\
\hline & 18. My supervisor and colleagues often praise me behind my back. \\
\hline & 19. My supervisor and colleagues will tell me good and useful news. \\
\hline
\end{tabular}

Strategic countermeasure ability (SCA)

\begin{tabular}{|c|c|}
\hline \multirow{3}{*}{$\begin{array}{l}\text { Assisting } \\
\text { strategy-making }\end{array}$} & 1. The HR department plays a strategic decision-making role in business management. \\
\hline & 2. The HR department has a cooperative relationship with other functional departments. \\
\hline & 3. The HR department participates in the establishment of business strategy. \\
\hline \multirow{3}{*}{$\begin{array}{l}\text { Strengthening } \\
\text { departments' } \\
\text { cooperation }\end{array}$} & 4. The HR strategy considers the needs of all functional departments. \\
\hline & 5. The HR management system is quite reasonable. \\
\hline & 6. The HR management system has been implemented effectively. \\
\hline \multirow{3}{*}{$\begin{array}{l}\text { Strategic } \\
\text { positioning of HR } \\
\text { department }\end{array}$} & 7. Senior administrators all think that the HR department is very important. \\
\hline & 8. Business leaders strongly support the HR department. \\
\hline & 9. When formulating business strategy, high-level managers fully consider the HR department's advice. \\
\hline
\end{tabular}

Organisational attractiveness $(\mathrm{OA})$

1. The HR department in my company has designed a nice, useful recruitment brochure.

2. Recruiters in my company are of high quality.

3. The HR department in my company pays much attention to developing recruitment materials.

4. The HR department in my company displays a high level of professional skills in recruitment.

5. Recruitment seminars of my company are rich in content, attractive and creative. 
Regulatory mechanism (RM)

\begin{tabular}{|c|c|}
\hline \multirow{3}{*}{$\begin{array}{l}\text { Observing the } \\
\text { law and } \\
\text { regulations }\end{array}$} & $\begin{array}{l}\text { 1. The HR department in my company establishes internal employees' minimum wages according to the } \\
\text { minimum-wage law. }\end{array}$ \\
\hline & $\begin{array}{l}\text { 2. The HR department in my company establishes a compensation system according to legal welfare } \\
\text { regulations. }\end{array}$ \\
\hline & $\begin{array}{l}\text { 3. The HR department in my company supervises organisation management so as to make the } \\
\text { organisation observe laws and regulations. }\end{array}$ \\
\hline \multirow{2}{*}{$\begin{array}{l}\text { Contribution } \\
\text { to culture } \\
\text { construction }\end{array}$} & 4. The HR department in my company actively participates in corporate culture construction. \\
\hline & 5. The HR department in my company integrates social responsibility into corporate culture construction. \\
\hline
\end{tabular}

\section{Sustainable business philosophy (SBP)}

1. The HR department in my company often conveys a sense of environmental protection to internal employees.

2. The HR department in my company often directs decision makers and ordinary staff to observe the environmental protection law.

3. The HR department in my company endeavours to strengthen corporate image maintenance.

4. The HR department in my company pays much attention to improving professional skills.

5. The HR department in my company is concerned about cooperating with the government and non-profit organisations.

\section{Client orientation (CO)}

1. The HR department in my company endeavours to improve its service quality and quantity.

2. An important strategic aim for the HR department in my company is to meet the demands of its clients.

3. The HR department in my company endeavours to understand its clients' demands.

4. The HR department in my company places great emphasis on customer satisfaction.

5. The HR department in my company places great emphasis on developing new management notions and systems.

\section{Organisational performance}

\section{New-product performance (NPP)}

1. How do you think the number of new products of your company in the annual business cycle compared with that of other firms in the same industry?

2. How do you think the sales revenue of your company in the annual business cycle compared with that of other firms in the same industry?

3. How do you think the market share of the new products in your company compared with that of other firms in the same industry?

\section{Business financial performance (BFP)}

1. How do you think the profit of your company during the past three years compared with that of other firms in the same industry?

2. How do you think the total sales of your company during the past three years compared with that of other firms in the same industry?

3. How do you think the total return on assets of your company during the past three years compared with that of other firms in the same industry?

4. How do you think the total sales growth of your company during the past three years compared with that of other firms in the same industry?

5. How do you think the market share of your company during the past three years compared with that of other firms in the same industry?

6. How do you think the total asset growth of your company during the past three years compared with that of other firms in the same industry?

\section{Human capital (HUC)}

1. What do you think of your company's investment in human resources training, recruitment and compensation?

2. Are you satisfied with working in the company?

3. How do you think the productivity of internal employees compared with that of other firms?

4. What do you think of the general operational capability of internal employees in your company? 